\title{
What is Hidden in Colours? An Empirical Study on the Perception of Colours by Youth in India
}

\author{
Ramanathan H.N. ${ }^{1}$, De Alwis A.C. ${ }^{2}$, Murali V. ${ }^{3}$ \\ ${ }^{1}$ Department of Management Studies, JAIN (Deemed-to-be University) Kochi Campus \\ Knowledge Park, Nirmal Infopark, Infopark P.O., Kakkanad, Koch, India \\ ${ }^{2}$ Department of Human Resource Management, University of Kelaniya, Sri Lanka \\ ${ }^{3}$ Department of Management Studies, Toc H Institute of Science and Technology, \\ Arakkunnam, Kochi, Kerala, India \\ ${ }^{1}$ hareeshramanathan@gmail.com, ${ }^{2}$ chamaru@kln.ac.lk, ${ }^{3} \mathrm{vm} 8090 @$ gmail.com
}

\begin{abstract}
Colour is an inexpensive and effective tool used to create a positive opinion of the consumers about the brand/product. The colour has a powerful impact on all the life aspects at the subconscious level. The primary purpose of this study is to find the correspondence between the perception attributes associated with colours, and the study had examined the relationship between colour and attributes in a multidimensional space. Questionnaires were used to collect the data. The research design was descriptive. The target population for the present research is focused on youth in India in the age group of 20-25 years and the number of respondents selected for conducting the study was 120 . Six colours were taken, and the correspondence of these colours with the attributes was mapped in a two-dimensional space. When correspondence analysis test was conducted, it was found that royal attribute is closely associated with is closer to trustworthy attribute, green is closer to attributes such as faith, nurturing, safety and warmth and white is closer to attributes such as faith and trustworthy which signifies that different colours have a different perpetual impact on consumers.
\end{abstract}

Keywords: Attributes of colours, Correspondence analysis, Perception of colours, Youth

Copyright: (C) 2020 Ramanathan H.N., De Alwis A.C. and Murali V. This is an open access article distributed under the Creative Commons Attribution License, which permits unrestricted use, distribution, and reproduction in any medium, provided the original work is properly cited.

Correspondence: hareeshramanathan@gmail.com

ORCID of authors: Ramanathan H.N., - (D) https://orcid.org/0000-0001-6342-399X

De Alwis A.C - (D https://orcid.org/0000-0003-2492-9466

Murali V. $\quad$ - (D https://orcid.org/0000-0001-5915-8812

DOI: http://doi.org/10.4038/kjm.v9i2.7645 


\section{Introduction}

The modern society is a society of consumers. Nowadays because of globalisation and competition, convincing the consumers is not an easy task. It is believed that immaterial and intangible elements of the product affect the consumers' buying decisions. The competitive scenario obliges the companies to use actively the marketing tools, which would create exclusivity and innovation which is the link with the consumer and recognition of brands. Some scientists argue that the classical marketing techniques are not sufficient any more. The innovative marketing dictates the new era. It suggests that companies are using all the human senses: sight, sound, smell, taste and touch for addressing the consumers. The sensory marketing is found to be the innovative solution which can create the emotional characteristics of the brand and to provide the same with a stable position in the market, as well as to bring strong relations with a consumer (Silva, Teixeria, \& Luchini, 2018). The sensory marketing provides greater opportunity to use colour as the tool to form the product's differentiation. The colours will create emotional relationships which are resulting in differentiation of the products and brands which in turn create acquired competitive advantage, reinforced loyalty, increased sales, shorter perception time of the brand mark, the more extended stay of consumers in the store, created positive emotions and relationship with the consumer, which encourage to buy on impulse, an increased number of intentions to go shopping again. Colour is an inexpensive and effective tool used to create a favourable opinion of the consumers about the brand/product. The colour psychology affects the human lives in many ways; however, they often do not perceive the impact of selected colours for a website, shop or office, when the marketing techniques are implemented or when the clothes for the employees are selected and used. The colour has a powerful impact on all the life aspects of the subconscious level. Even when no word is told, the understanding of the meaning of colours in the business provides with a priceless tool to obtain the best response to marketing and to create the booming business in the end. The studies of the scientific literature (Sliburyte \& Skeryte, 2014) allow stating that the discussions on the element of sensory marketing - colour, are still very few in the marketing literature. This shortage is mostly felt in the Lithuanian market. There is not enough systemised information about the usage of colours in the Lithuanian market, and as we know, the consumers' colour perception depends majorly on the culture. In majority of the researches conducted by the scientists regarding the colour and the influence of the same on people were done in the areas of medicine, psychology and others. There is lack of generalised material, where the information about colour usage in marketing decisions would be stated systematically, and this allows formulating the research problem in question - how does the consumers' colour perception influence the marketing decisions.

\section{Research Gap}

Scientific findings on colour theory appear to be as contentious as the research on lighting's effects. Conventional psychologists may dismiss any role of colour in influencing human personality, yet psychiatrists use colour tests with other tests to determine once personality. While physiological responses to colours are part of the human experience, the evidence linking specific colours to specific responses is inconclusive (Kaiser, 1984). Colours appear to be contentious. The absence of scientific results relating to colour has given rise to several confusions. There have been 
some developments in the research, although it came from companies in the colour consultation industry. The results seem to be in agreement among marketers. It points out the use of colour in attracting consumers. Several studies were contributing much to the relationship of colours with the marketing of products and otherwise. Colour perception is one of the critical factors in textile and garment areas. Research work was carried to discover the physiological and psychological influences of the colour vision on the designers and consumers (Chen, 2004). A study by (Jacobs, Keown, Worthley, \& Ghymn, 1991) had used the Lüscher colour test is used to compare colour associations in different countries. Respondents were asked which colour they would like to associate with words such as expensive, happy, love and dependable. The respondents were also asked to relate the colours to countries; institutions and product packages, such as a soft drink label and a box of headache remedy. The findings show that, some colours seem to show cross-cultural consistency, other colours, such as purple and grey, hold opposite meanings in different cultures. However, all these were pertaining to the preference of colours for a particular product or not. Apparently what attributes are associated with what all colours is not explored much, and hence this study is focusing on the gap identified.

\section{Problem statement}

Colours play a vital role in life for taking decision for different objects that expect by the consumer. People were used to describing the colour perception on their own understanding by words. Peoples moods, feelings and mental state are unstable and that colours play roles in forming attitude. Several studies have identified the association of the same with countries, products and places. Even though there are many studies specifying the significance of colours, none of the studies is attempted to identify the perception attributes associated with colours. Nevertheless, what connotation people attribute with each colour may be different from person to person and from region to region. It is important to know what customers' perception towards colour are and what connotations it do have. This study attempts to find the correspondence between perceptions attributes regarding colours.

\section{Objective}

To find the correspondence between the perceptions attributes associated with different colours in a multidimensional space.

\section{Review of Literature}

Are you selling the right colour? A crosscultural review of colour as a marketing cue (Aslam, 2005), this paper reviews the psychological and socio-cultural associations and meanings of colour(s) in a cross-cultural marketing perspective and outlines its role as a marketing cue. It is argued that a cross-cultural perspective of colour research and application is imperative for developing global marketing strategies, and the cultural values, marketing objectives and desired customer relationship levels would dictate the choice of colour in corporate and marketing communications in the 21st Century. Identifying appropriate colour-culture clusters also facilitates the development of a colour theory in marketing. The study indicates that good work lies ahead in this area to energise marketing communications in the $21 \mathrm{st}$ Century. The meanings given to some colours may pan-cultural, some regional and some unique to specific cultures (Madden et al, 2000), and it is imperative to investigate the meaning and importance of chosen colour in the target market before the launch of the product or a promotion campaign (Jacobs, 1991). An 
interpretative model of colour application in marketing is proposed in this study.

However, another study was conducted (Conway, Pelet, Papadopoulou, \& Limayem, 2010) in using colour to change the perception of quality in ecommerce sites. E-commerce sites, like their brick-and-mortar cousins, are designed to draw in potential customers and encourage purchases and brand loyalty. Currently, E-commerce website designs are often rejected by their user community, which costs money through wasted development and lost customers. Another study was conducted on colours across Cultures (Bortoli \& Maroto, 2001). The study of the impact of colours on internet surfers and consumers has been extensive, but it is still at the beginning as far as cross-cultural localisation is concerned. Colour has an impact on every moment in life. It is a vital marketing communication tool, a unique visual element and carries essential symbolic and associative information about products (Garber, Hyatt, \& Starr, 2000). It explosively influences the clothes we wear, the car that we drive, the backpack or handbag that we choose to use, the shoes or sneakers we wear and the furnishings in our homes. The product's colour might play a remarkable role in the consumer's purchasing decisions for certain products (Akcay \& Dalgin, 2011). The findings of this study support the notion that colour has an influence on the arousal experienced by a shopper (Valdez \& Mehrabian, 1994). The red retail environment was found to be significantly more arousing than the blue retail environment.

The red retail environment was found to be significantly more arousing than the blue retail environment. Complementing previous experiments (Jean, Michael, \& Sven, 1982), the fun shopper experiences more pleasure and approach tendency in a red retail environment. Run shoppers, on the other hand, show a slight preference for a blue retail environment.

Another study has been conducted on the universal colour grid (Areni \& Brady, 2009) colour research unbiased by verbal labels and prototypical hues. Colour research in marketing, particularly as it relates to branding, is limited by reliance on verbal labels to identify and categories colours. For example, discussing associations with the colour - green for branding food products makes little or no sense because numerous relevant associations would depend on the specific shade of green used (i.e., mint, lime, organic, etc.). Cultural differences exacerbate these issues. Certainly, colours on products may attract attention and convey information; in other words, colour is an influential design element (Jansson, Marlow, \& Bristow, 2004), (Kauppinen-Räisänen \& Luomala, 2010). The colours companies choose on their brands contribute to their brands standing out from other brands (Caivano \& Mabel, 2007). Consumers use colour to search for and identify brands. That is, colour is valuable in logo design and brand personality (Labrecque \& Milne, 2012). "Indeed, colour can be an important, controllable marketing variable for managing image standardisation because a product's colour can function not only as an immediate identifier of its brand but also it is quality and price" (Singh, 2006). Thus, on the one hand, the right colour can promote recognition of, for example, logotypes and products (Hultén, Broweus, \& Van Dijk, 2011), and it can maintain consumer's attention. On the other hand, the wrong colour choice may hamper any communication between a company and its target market. Choosing the wrong colour can hurt brand awareness and any attempt to build a sustainable brand image. The importance of choosing appropriate colours may be especially salient within the store environment as colours can affect perceptions of the merchandise. In a study 
conducted by (Kimle \& Fiore, 1992), it was found that when participants were shown advertisements in a magazine, the ads that contained the most colour were the focus of participant's attention. The relationship between colour and international branding has also been studied (Grimes \& Doole, 1998). In Grimes \& Doole's (1998) study, it was found that colour is a way in which people identify brands and colour association made with brands are internationally evident. Those from different cultures were able to associate certain colours with popular brands such as Marlboro and Guinness. In a study which tested the colour of a computer screen and time perception, it was found that when the screen was blue compared to yellow, participants felt more relaxed and perceived time to pass quickly (Gorn, Chattopadhayay, Sengupta, \& Tripathi, 2004)

To understand The Two-Dimensional Impact of Colour on Shopping, a study has been conducted by (Crowley, 1993). Prior research has typically grouped colour effects into a single class of effects and has ignored situational aspects of consumer responses to colour. In the present study, colour effects are shown to exhibit different patterns depending on the type of response examined. Further, these effects are described as a function of colour wavelength. Evaluative effects are most positive at the short-wavelength (blue) end of the visible spectrum, while the activation response engendered by colour exhibits a U-shaped pattern across wavelengths. In this paper, it was posited that there are at least two dimensions within the human response to colour. This "two-dimensional hypothesis was supported by the results. Retail store environments in the more extreme wavelength colours (red and blue) were perceived as more active environments.

Wexner (1954) examined the associations between colour and mood. Participants were faced with coloured cards and asked to indicate associations with different moods. Cool colours were associated with calm, serene and comfortable moods. In contrast, warm colours were associated with stressful and exciting moods. However, the participants in the study were only exposed to coloured cards and not actually located in a coloured environment. According to Wexner, there is a relationship between wavelength and level of arousal (Wexner, 1954). These findings were later confirmed by (Valdez \& Mehrabian, 1994), who found that long-wavelength colours were more arousing than shortwavelength colours. To attract customer, colour is considered to be a crucial factor. Being acquainted with the psychological impact of colours and their different combinations would be of great help to designers. Designers pick out a particular colour based on the nature of the product (Rouland, 1999). In addition, particular colours could be signified by marketers by using association theory and be used as an experimental sign or image expansion. Research on -Colour scheming $\|$ is gaining increased awareness and popularity among the number of marketing researchers. The main reason behind this is that the human brain receives signals faster through eyes rather than ears. (Young, 1802) Supported this by showing the impact of the luminous body and its coloured particles, when they get into the eyes of a human being. It's obvious that one feels the visuals readily and uses other senses afterwards. By using different methods, we can increase the quality of visuals used in ads and packaging. Nowadays, we see that product with an effective colour scheming gains success in consumers while many products fail due to poor colour scheming. The brightness of colours and their saturation levels have different impacts according to the saturation level. (Palmeri, Blake, Marois, \& Flanery, 2002). 


\section{Research Methods}

The research design used for the study is descriptive in nature. Descriptive design results in a description of the data, whether in words, pictures, charts or tables and whether the data analysis shows statistical relationships or is merely descriptive. Data was collected directly from the respondents with the help of a questionnaire using Google forms. The convenience sampling method is being used for data collection, and the target population for the present research is focused on youth who are in between the age group of 20 to 25 years from the state of Kerala in India. The number of respondents selected for conducting the study was 120 .

Relevancy and accuracy are two major concerns associated with questionnaire design. Relevancy refers to questions being asked that are relevant to the identified variables, whereas accuracy refers to information that is reliable and valid (Zikmund, 2003). Generally, it relates to principles of wording, which include content and length, wording and language, and form of questions. Content of questions should properly measure respondents' attitudes, beliefs, and opinions based on the variables of a conceptual model (Sekaran, 2000). Words and wording used for this research were reviewed for further corrections to ensure that the questions being asked are well understood by the respondents. This ensured that the questions were developed based on the art of asking questions, which is using simple and conversational language, and avoiding leading and ambiguous questions (Zikmund, 2003).

The questionnaire is divided into three sections - in the first section information were collected on age, gender, educational qualification and profession of the respondent etc. The second section was designed to collect information regarding colours in an ordinal format. The next section, which is the third one, was used to understand the correspondence between the perceptions attributes associated with colours. The cultural symbolism of colours was extracted from M (2005). The colour attributes were referred to (Canva, 2019). Six elementary colours were used, and fifteen attributes of colours were identified for the study. Then the further direction of the study was oriented towards the correspondence between colours and these attributes.

Correspondence analysis is a descriptive/exploratory technique designed to analyse simple two-way and multi-way tables containing some measure of correspondence between the rows and columns. The measure of correspondence can show the similarity, affinity, confusion, association or interaction among rows and columns.

The major tool used for the analysis was correspondence analysis. The major goals of correspondence analysis is to explain the relationships between two nominal variables in a correspondence table, while simultaneously describing the relationships between the categories for each variable. For each variable, the distances between category points in a plot reflect the relationships between the categories with similar categories plotted close to each other. Projecting points for one variable on the vector from the origin to a category point for the other variable describe the relationship between the variables (IBM Knowledge Center, 2018).

The data is processed mathematically by the following derivations (Greenacre, 2017).

Compute the proportion matrix, $\mathrm{P}$, by dividing the elements of $\mathrm{K}$ by the total of all numbers in K. Mathematically. 
Table 01: Variables Used for the Study

\begin{tabular}{|c|c|c|}
\hline Colours Considered & Attributes & Attributes \\
\hline Blue & Vibrant & Royal \\
\hline Red & Trustworthy & Elegant \\
\hline Black & Attention & Faith \\
\hline Yellow & Pessimistic & Hope \\
\hline Green & Happiness & Safety \\
\hline 9White & Illness & Security \\
\hline & Loyalty & Nurturing \\
\hline & Warmth & \\
\hline
\end{tabular}

Source: Survey data

$$
\mathbf{P}=\left\{p_{i j}\right\}=\left\{k_{i j} / k_{. .}\right\}
$$

Compute the row distances, di, and the column distances, dj.

$$
\begin{gathered}
d_{i}=\sum_{j}\left(\frac{1}{p_{. j}}\right)\left(\frac{p_{i j}}{p_{i .}}-p_{. j}\right)^{2} \\
d_{j}=\sum_{i}\left(\frac{1}{p_{i .}}\right)\left(\frac{p_{i j}}{p_{. j}}-p_{i .}\right)^{2}
\end{gathered}
$$

\section{Analysis and Discussion}

Two variables were considered for the analysis namely colour and the other is attributes. The variable 'colour' is represented as rows, and the variable 'attribute' is represented as a column. This table is called the correspondence table, and the values given in the table are called as score or frequency. In table 1 , the respondents have opted 'royal' as the best attribute for the colour blue, 'vibrant' as the best attribute for the colour red, 'elegant' as the best attribute for the colour black, 'vibrant' as the best attribute for the colour yellow, 'faith' and 'happiness' as the best attribute for the colour green and 'hope' as the best attribute for the colour white. Majority of the people responded to the colours white and red. Same as in the case of attributes, the major portion of the respondents preferred the attributes royal and happiness.

Inertia per dimension shows the decomposition of the total inertia along each dimension. Two dimensions account for $71 \%$ of the total inertia. Adding the third dimension adds only $14 \%$ to the accounted-for inertia. Thus, it is decided to use a two-dimensional representation.

Inertia per dimension shows (Table 2) the decomposition of the total inertia along each dimension. Two dimensions account for $71 \%$ of the total inertia. Adding the third dimension adds only $14 \%$ to the accounted-for inertia. Thus, it is decided to use a two-dimensional representation.

Table 3 displays that colour black contribute the most to the first dimension, whereas red contribute the most to the second dimension. Colours yellow and blue lie close to the origin. As green and white lie close to the zero points, they cannot be categorised in the dimensions 
Ramanathan H.N., De Alwis A.C., Murali V., KJM, 2020, 09 (02)

Table 02: Correspondence Table

\begin{tabular}{|c|c|c|c|c|c|c|c|c|c|c|c|c|c|c|c|c|}
\hline \multirow[b]{2}{*}{$\frac{\mathscr{0}}{\stackrel{0}{0}}$} & \multicolumn{16}{|c|}{ Attributes } \\
\hline & 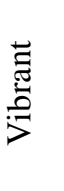 & 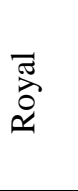 & 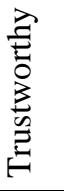 & 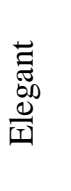 & . & 营 & 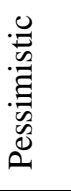 & 䒘 & 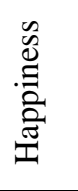 & 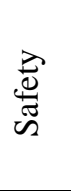 & 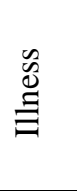 & 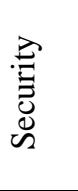 & 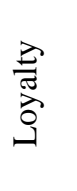 & 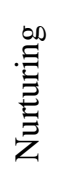 & 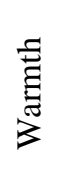 & 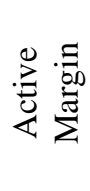 \\
\hline Blue & 20 & 48 & 20 & 34 & 19 & 11 & 10 & 19 & 33 & 7 & 1 & 8 & 14 & 3 & 12 & 259 \\
\hline Red & 47 & 28 & 7 & 14 & 46 & 8 & 5 & 11 & 14 & 10 & 7 & 5 & 4 & 2 & 7 & 215 \\
\hline Black & 9 & 19 & 9 & 29 & 24 & 9 & 18 & 3 & 7 & 13 & 19 & 14 & 13 & 8 & 13 & 207 \\
\hline Yellow & 29 & 22 & 24 & 22 & 13 & 9 & 2 & 15 & 23 & 4 & 9 & 6 & 11 & 15 & 21 & 225 \\
\hline Green & 12 & 11 & 10 & 19 & 12 & 17 & 5 & 31 & 29 & 18 & 4 & 14 & 16 & 21 & 15 & 234 \\
\hline White & 7 & 23 & 26 & 20 & 15 & 33 & 9 & 38 & 33 & 17 & 4 & 8 & 16 & 13 & 20 & 282 \\
\hline $\begin{array}{l}\text { Active } \\
\text { Margin }\end{array}$ & 124 & 151 & 96 & 138 & 129 & 87 & 49 & 117 & 139 & 69 & 44 & 55 & 74 & 62 & 88 & 1422 \\
\hline
\end{tabular}

Table 03: Summary

Dimen Singular Inertia Chi- Sig. Proportion of Inertia Confidence Singular -sion Value Square Value

\begin{tabular}{|c|c|c|c|c|c|c|c|c|}
\hline & & & & & for & -e & Deviation & 2 \\
\hline 1 & .342 & .117 & & & .459 & .459 & .026 & .060 \\
\hline 2 & .254 & .065 & & & .254 & .712 & .029 & \\
\hline 3 & .192 & .037 & & & .145 & .857 & & \\
\hline 4 & .158 & .025 & & & .098 & .955 & & \\
\hline 5 & .107 & .012 & & & .045 & 1.000 & & \\
\hline Total & & .255 & 362.295 & $.000^{\mathrm{a}}$ & 1.000 & 1.000 & & \\
\hline
\end{tabular}

a. 70 degrees of freedom

Source: Survey Data

Table 04: Overview Row Points

\begin{tabular}{|c|c|c|c|c|c|c|c|c|c|}
\hline \multirow{3}{*}{ Colours } & \multirow{3}{*}{ Mass } & \multicolumn{2}{|c|}{$\begin{array}{c}\text { Score in } \\
\text { Dimension }\end{array}$} & \multirow{3}{*}{ Inertia } & \multicolumn{5}{|c|}{ Contribution } \\
\hline & & \multirow[t]{2}{*}{1} & \multirow[t]{2}{*}{2} & & \multicolumn{2}{|c|}{$\begin{array}{l}\text { Of Point to } \\
\text { Inertia of } \\
\text { Dimension }\end{array}$} & \multicolumn{3}{|c|}{$\begin{array}{l}\text { Of Dimension to Inertia } \\
\text { of Point }\end{array}$} \\
\hline & & & & & 1 & 2 & 1 & 2 & Total \\
\hline Blue & .182 & .085 & -.261 & .028 & .004 & .049 & .016 & .111 & .127 \\
\hline
\end{tabular}


Ramanathan H.N., De Alwis A.C., Murali V., KJM, 2020, 09 (02)

\begin{tabular}{|c|c|c|c|c|c|c|c|c|c|}
\hline Red & .151 & 1.106 & -.389 & .076 & .541 & .090 & .829 & .077 & .906 \\
\hline Black & .146 & .294 & 1.188 & .057 & .037 & .808 & .076 & .920 & .996 \\
\hline Yellow & .158 & .015 & -.235 & .022 & .000 & .035 & .001 & .101 & .102 \\
\hline Green & .165 & -.611 & .009 & .035 & .180 & .000 & .608 & .000 & .608 \\
\hline White & .198 & -.642 & -.155 & .037 & .239 & .019 & .753 & .033 & .786 \\
\hline $\begin{array}{c}\text { Active } \\
\text { Total }\end{array}$ & 1.000 & & & .255 & 1.000 & 1.000 & & & \\
\hline
\end{tabular}

a. Symmetrical normalisation

Source: Survey Data

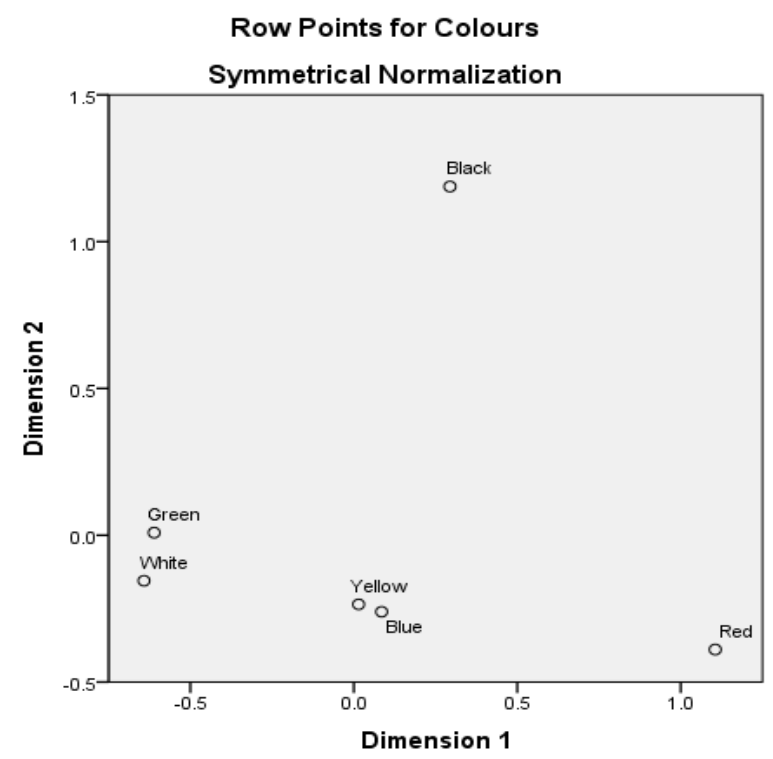

Source: Survey Data

Figure 1: Row Points for Colours

Table 05: Overview Column Points

\begin{tabular}{|c|c|c|c|c|c|c|c|c|c|}
\hline \multirow{3}{*}{ Attributes } & \multirow{3}{*}{ Mass } & \multicolumn{2}{|c|}{$\begin{array}{c}\text { Score in } \\
\text { Dimension }\end{array}$} & \multirow{3}{*}{ Inertia } & \multicolumn{5}{|c|}{ Contribution } \\
\hline & & \multirow[t]{2}{*}{1} & \multirow[t]{2}{*}{2} & & \multicolumn{2}{|c|}{$\begin{array}{l}\text { Of Point to } \\
\text { Inertia of } \\
\text { Dimension }\end{array}$} & \multicolumn{3}{|c|}{$\begin{array}{l}\text { Of Dimension to } \\
\text { Inertia of Point }\end{array}$} \\
\hline & & & & & 1 & 2 & 1 & 2 & Total \\
\hline Vibrant & .087 & 1.060 & -.655 & .048 & .286 & .147 & .701 & .199 & .899 \\
\hline Royal & .106 & .377 & -.247 & .019 & .044 & .026 & .279 & .089 & .368 \\
\hline Trust worthy & .068 & -.316 & -.280 & .011 & .020 & .021 & .207 & .121 & .328 \\
\hline Elegant & .097 & .059 & .343 & .008 & .001 & .045 & .014 & .345 & .359 \\
\hline
\end{tabular}


Ramanathan H.N., De Alwis A.C., Murali V., KJM, 2020, 09 (02)

\begin{tabular}{cccccccccc}
\hline Attention & .091 & .970 & .011 & .035 & .250 & .000 & .840 & .000 & .840 \\
\hline Faith & .061 & -.639 & -.107 & .015 & .073 & .003 & .576 & .012 & .588 \\
\hline Pessimistic & .034 & .171 & 1.205 & .016 & .003 & .197 & .021 & .787 & .809 \\
\hline Hope & .082 & -.711 & -.498 & .022 & .122 & .080 & .640 & .234 & .874 \\
\hline Happiness & .098 & -.383 & -.453 & .011 & .042 & .079 & .434 & .451 & .885 \\
\hline Safety & .049 & -.270 & .359 & .009 & .010 & .025 & .139 & .182 & .321 \\
\hline Illness & .031 & .567 & 1.509 & .025 & .029 & .277 & .136 & .717 & .853 \\
\hline Security & .039 & -.174 & .720 & .007 & .003 & .079 & .054 & .688 & .742 \\
\hline Loyalty & .052 & -.413 & .282 & .005 & .026 & .016 & .667 & .231 & .899 \\
\hline Nurturing & .044 & -.761 & .163 & .018 & .074 & .005 & .468 & .016 & .484 \\
\hline Warmth & .062 & -.303 & .075 & .006 & .017 & .001 & .345 & .016 & .361 \\
\hline Active Total & 1.000 & & & .255 & 1.000 & 1.000 & & & \\
\hline
\end{tabular}

a. Symmetrical normalization

Table 04 displays that Illness and pessimistic both contribute a substantial portion to the inertia of the first dimension. Illness and attention contribute the largest amounts to the inertia of the second dimension. In the table, trustworthy, hope and happiness contribute very little to either dimension. IThe column points plot shows that warmth and trustworthy are both very close to the origin, indicating that they differ little from the average column profile.

The colours Red and Green show a positive correlation (Table 5) whereas Blue, Black, Yellow and White show a negative correlation.

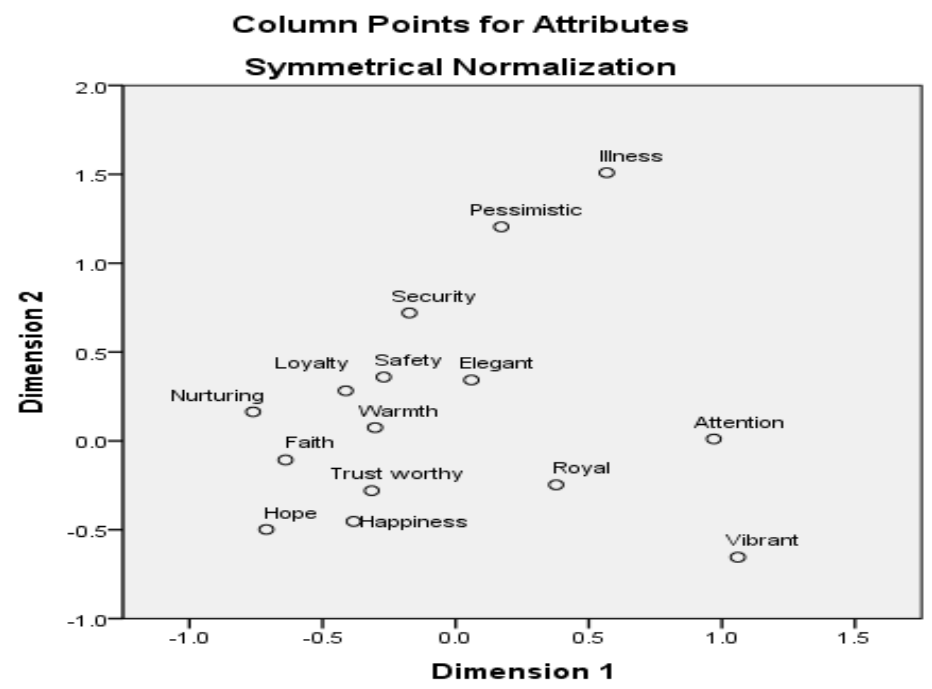

Figure 2: Column Points for Colours 
Table 06: Correlations

\begin{tabular}{cccc}
\hline \multirow{2}{*}{ Colours } & \multicolumn{2}{c}{ Standard Deviation in Dimension } & Correlation \\
\cline { 2 - 4 } & 1 & 2 & $1-2$ \\
\hline Blue & .154 & .264 & -.035 \\
\hline Red & .145 & .237 & .486 \\
\hline Black & .282 & .094 & -.566 \\
\hline Yellow & .152 & .213 & -.011 \\
\hline Green & .121 & .229 & .027 \\
\hline White & .095 & .169 & -.192 \\
\hline
\end{tabular}

Source: Survey Data

From figure 03, it has been found that royal attribute is closely associated with blue colour, a vibrant attribute associated with red colour. However, there are studies which pointed out that blue is consistently identified as the most preferred or most pleasant hue and yellow and orange are less liked (Crozier, 1999). In literature, it is often mentioned that red is a warm and blue a cool colour (Bakker, 2013).

Interestingly, this study proves that black is closer to the pessimistic attribute, and yellow is closer to trustworthy attribute. Yellow is the brightest colour and yellow is a warm colour of sunshine. It is the colour of happiness, mental clarity, optimism, cheerfulness, and energy. It is also a colour that stimulates appetite, the brain, and memory, leading to confidence. It is proved that studying in yellow rooms enhances focus. Yellow is a practical colour, it makes one more analytical, as it is mainly perceived by the brain, and a lot lesser by the heart M (2005).

This research proves that green is closer to attributes such as faith, nurturing, safety and warmth. There are other research findings which signify this view. Green is a colour that does not stress the eyes. Green also relaxes the nervous system and calms the spirit, enhances one's mood and behaviour. Darker shades define prestige, wealth, and money. Lighter greens will make you feel fresh.
White is closer to attributes such as faith and trustworthy. While the colour of red on the skin is an iconic sign of heat, it may also be an indexical sign of embarrassment, fever and fire. Similarly, blue on the skin may convey coldness, whereas black may convey gangrene. In nature, the colour brown may be an indexical sign of dryness, a black sky may be an index of impending storms, and black smoke is an index of fire. In a similar vein, yellow may be exemplified on packages as an indexical sign. As the sun is a source of energy, a sign-object relationship exists between yellow and energy (Räisänen \& Jauffret, 2018).

Different colours have a different perpetual impact on consumers. Majority of the respondents preferred the colours because it dramatically influences the buying behaviour of customers and that marketers have a higher chance of influencing people for purchase by using those colour.

\section{Conclusion}

Colours can arouse the interest and thus increase the desire to purchase the product. Colours in marketing directly affect consumer behaviour and the effects of colours determine the behaviour of many consumers. The results of this study indicate that colours can stimulate interest and increase the desire to purchase the product. Consumers consider some 


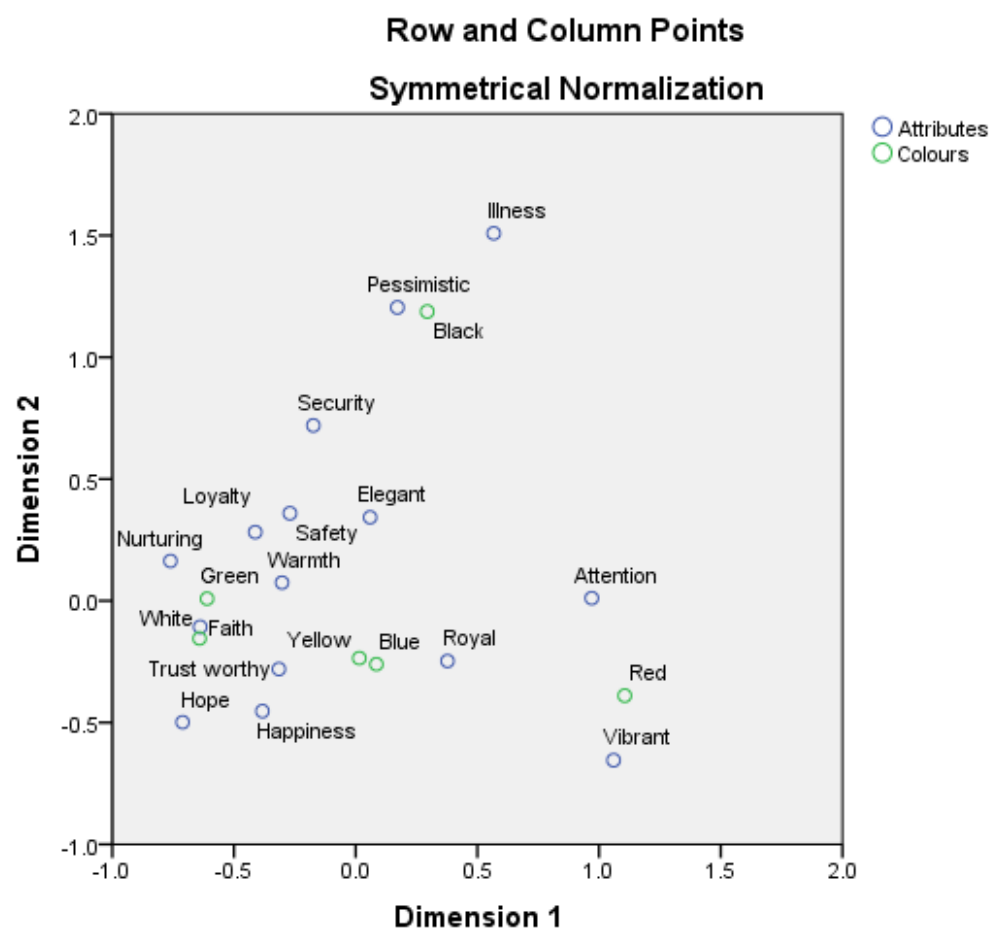

Figure 03: Row and Column Points for Colours

colours as associated with specific products which make the understanding of how people react to colours much more difficult. Each colour must be used in a suitable product according to its psychological characteristics. Depending upon the target audience managers should choose colours for products. Research relating to the choice of colours should be conducted and concluded before launching a product, as the wrong colour choice can have a negative impact on the image of the product and the company.

Every respondent had differing perceptions of the primary colours. Each colour was associated with different attributes to understand how each of these colours is perceived in the consumer's mind. Each respondent and conclusion differently ranked the colours were drawn based on their responses. It was found that among the given set of colours, blue was the most preferred colour, and black was the least preferred colour. It was also found that blue colour is closely associated to royal attribute, red colour is closely associated to vibrant attribute, black colour is closely associated to pessimistic attribute, the yellow colour is closely associated to trustworthy attribute, green colour is closely associated to attributes such as faith, nurturing, safety and warmth and white colour is closely associated to attributes such as faith and trustworthy. From this study, it was identified that the majority of the respondents preferred the colour blue, which shows that colour blue greatly influence the buying behaviour of customers.

\section{References}

Akcay, O., \& Dalgin, H. (2011). Perception of Color in Product Choice among College Students: A CrossNational Analysis of USA, India, China and Turkey. International journal of 
Business and Social science Available from: https://www. Semantic scholar.org/paper/Perception-of-Color-inProduct-Choice-among-College-AkcayDalgin/146768afd826131ee5cd9cf0956c d2 21a1b05372

Areni, C., \& Brady, C. (2009). The universal colour grid: colour research unbiased by verbal labels and prototypical labels (Thesis) ANZMAC, 01-06. Available from:1-6. https://ro.uow.edu.au/gsbpapers/501

Aslam, M. M. (2006). Are You Selling the Right Colour? A Cross-cultural Review of Colour as a Marketing Cue. Journal of Marketing Communications, 12(1), 1530, doi: 10.1080/13527260500247827

Bakker, I., Van der Voordt, T. J. M., de Boon, J., \& Vink, P. (2013). Red or blue meeting rooms: does it matter? Facilities, 31(1/2), 68-83, doi: $10.1108 / 02632771311292527$

Caivano, J. L., \& Mabel, A. (2007). Chromatic Identity in Global and Local Markets: Analysis of Colours in Branding. Journal of the International Colour Association, 1(3), 1-14.

Canva. (2019, January 10). Basic Colour Theory. Retrieved from: https://www.canva. com/learn/colormeanings-symbolism/

Crowley, A. E. (1993). The twodimensional impact of color on shopping. Marketing Letters, 4(1), 59-69. doi: 10.1007/bf00994188

Crozier, W. R. (1999). The meanings of colour: preferences among hues. Pigment \& Resin Technology, 28(1), 6-14. doi.org/10.1108/03699429910252315

Conway, C. M., Pelet, J. E., Papadopoulou, P., \& Limayem, M. (2010). Coloring in the lines: Using color to change. Thirty First International Conference on Information Systems, Saint Louis, Missouri, USA
Garber, L. L., Hyatt, E. M., \& Starr, R. G. (2000). The Effects of Food Color on Perceived Flavor. Journal of Marketing Theory and Practice, 8(4), 59-72. doi.org/10.1080/10696679.2000.1150188 0

Gorn, G. J., Chattopadhyay, A., Sengupta, J., \& Tripathi, S. (2004). Waiting for the Web: How Screen Color Affects Time Perception. Journal of Marketing Research, 41(2), 215-225. doi.org/10.1509/jmkr.41.2.215.28668

Greenacre, M. (2017). Correspondence Analysis in Practice. Barcelona: CRC Press, Taylor \& Francis Group.

Grimes, A., \& Doole, I. (1998). Exploring the Relationships Between Colour and International Branding: A Cross Cultural Comparison of the UK and Taiwan. Journal of Marketing Management, 14(7), 799-817.

doi.org/10.1362/026725798784867581

Hultén, B., Broweus, N., \& Van Dijk, M. (2011). Sensory Marketing. The Journal of Product Innovation Management, 28(4), 613-615.doi.: 10.1111/j.15405885.2011008 29_1.x

IBM Knowledge Center. (2018, July). Correspondence analysis., IBM Knowledge Center: Retrieved from: https://www.ibm com/support/knowledgecenter/en/SSLV MB_24.0.0/spss/tutorials/correspondence _table.html

Jansson, C., Marlow, N., \& Bristow, M. (2004). The influence of colour on visual search times in cluttered environments. Journal of Marketing Communications, 10(3), 183-193.

doi.:10.1080/1352726042000207162

Kaiser, P. K. (1984). Physiological response to color: A critical review. Color Research \& Application, 9(1), 29-36. doi. 10.1002/col.5080090106

Kauppinen-Räisänen, H., \& Luomala, H. T. (2010). Exploring consumers' product- 
specific colour meanings. Qualitative Market Research: An International Journal, 13(3), 287-308. doi. $10.1108 / 13522751011053644$

Kimle, P. A., \& Fiore, A. M. (1992). Fashion Advertisements: A Comparison of Viewers' Perceptual and Affective Responses to Illustrated and Photographed Stimuli. Perceptual and Motor Skills, 75(3_suppl), 1083-1091. doi.:10.2466/pms.1992.75.3f.1083

Labrecque, L., \& Milne, G. (2012). Exciting red and competent blue: the importance of color in marketing. Journal of the Academy of Marketing Science, 40(2), 711-740.

M. (2005, January 13). The Power of Colors: Meanings, Symbolism, and Effects on the Mind. Psychologenie. Retrieved from: https://psychologenie.com/the-power-ofcolors-their-meanings

Madden, T. J., Hewett, K., \& Roth, M. S. (2000). Managing Images in Different Cultures: A Cross-National Study of Color Meanings and Preferences. Journal of International Marketing, 8(4), 90-107. Doi:10.1509/jimk.8.4.90.19795

Palmeri, T. J., Blake, R., Marois, R. M., \& Flanery, M. (2002). The Perceptual Reality of Synesthetic Colors. Proceedings of the National Academy of Sciences of the United States of America, 6(99), 4127-4131.

Kauppinen-Räisänen, H., \& Jauffret, M.N. (2018). Using colour semiotics to explore colour meanings. Qualitative Market Research: An International Journal, 21(1), 101-117. doi. 10.1108/qmr-03-2016-0033
Rouland, R. (1999). What color are your school supplies? Direct Marketing, 1(2), 60-62.

Sekaran, U. (2000). Research Methods for business: A Skill Building Approach. Singapore: John Wiley \& Sons, Inc.

Silva, L. C. Teixeria R.C., \& Luchini A DM. (2018). Sensory marketing: A Strategic Tool to win and Keep Customers. Multidisciplinary Core Scientific Journal of Knowledge, 6(5), 111-131.

Singh, S. (2006). Impact of color on marketing. Journal of Management Decision, 44(6), 783-789. doi.:10.1108/00251740610673332

Sliburyte, L., \& Skeryte, I. (2014). What We Know about Consumers' Color Perception. Procedia - Social and Behavioral Sciences, 156, 468-472. doi.:10.1016/j.sbspro. 2014.11.223

Valdez, P., \& Mehrabian, A. (1994). Effects of color on emotions. Journal of Experimental Psychology: General, 123(4), 394-409, doi.;10.1037/00963445.123.4.394

Wexner, L. (1954). The degree to which colors (hues) are associated with moodtones. Journal of Applied Psychology, 38, 432-435.

Young, T. (1802). XIV. An account of some cases of the production of colours, not hitherto described. (1802). Philosophical Transactions of the Royal Society of London, 92, 387-397. doi:10.1098/rstl.1802.0016

Zikmund, W. G. (2003). Business Research Methods (7 ed.). Ohio: Thomson SouthWestern 